\title{
Anthropometry and body composition of south Indian babies at birth
}

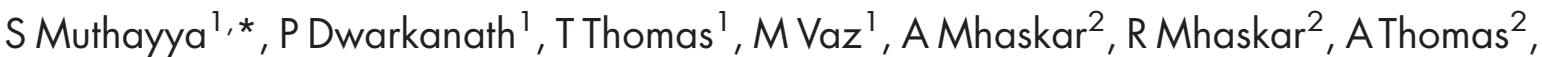 \\ S Bhat ${ }^{3}$ and AV Kurpad ${ }^{1}$ \\ ${ }^{1}$ Institute of Population Health and Clinical Research, St. John's National Academy of Health Sciences, Bangalore \\ 560 034, India: ${ }^{2}$ Department of Obstetrics \& Gynecology, St. John's Medical College Hospital, Bangalore, India: \\ ${ }^{3}$ Department of Pediatrics, St. John's Medical College Hospital, Bangalore, India
}

Submitted 22 August 2005: Accepted 10 January 2006

\begin{abstract}
Objectives: To assess the consequences on body composition of increasing birth weight in Indian babies in relation to reported values in Western babies, and to assess the relationship between maternal and neonatal anthropometry and body composition.

Design: Prospective observational study.

Setting: Bangalore City, India.

Subjects: A total of 712 women were recruited at $12.5 \pm 3.1$ weeks of gestation (mean \pm standard deviation, SD) and followed up until delivery; $14.5 \%$ were lost to follow-up. Maternal body weight, height, mid upper-arm circumference and skinfold thicknesses were measured at recruitment. Weight and body composition of the baby (skinfold thicknesses, mid upper-arm circumference, derived arm fat index and arm muscle index; AFI and AMI, respectively) were measured at birth in hospital.

Results: The mean \pm SD birth weight of all newborns was $2.80 \pm 0.44 \mathrm{~kg}$. Birth weight was significantly related to the triceps and subscapular skinfold thickness of the baby. In a small number of babies with large birth weight for gestational age, there was a relatively higher normalised AFI relative to AMI than for babies with lower or appropriate birth weight for gestational age. Maternal height and fat-free mass were significantly associated with the baby's length at birth.

Conclusions: Skinfold thicknesses in Indian babies were similar to those reported in a Western population with comparable birth weights, and the relationship of AFI to birth weight appeared to be steeper in Indian babies. Thus, measures to increase birth weight in Indian babies should take into account possible adverse consequences on body composition. There were no significant relationships between maternal anthropometry and body composition at birth on multivariate analysis, except for sum of the baby's skinfold thicknesses and maternal fat-free mass $(P<0.02)$.
\end{abstract}

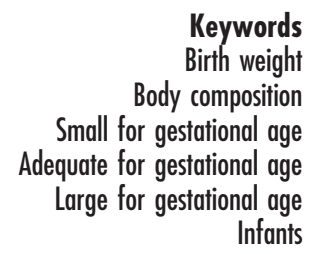

The prevalence of low birth weight (LBW) is high in Indian babies $^{1}$ and is a significant contributor to neonatal mortality $^{2}$. Therefore, the prevention of LBW is an important public health initiative, and this seems appropriate in the context of the observation that diabetes in adult life is more common in those born with $\mathrm{LBW}^{3}$. However, in Indian infants, increasing birth weight must be evaluated with regard to body composition at birth, since they are thought to have a similar amount of fat (assessed by one or two skinfold thicknesses) to Western infants even though their body weight is lower ${ }^{4,5}$, leading to their characterisation as 'thin-fat'. The relatively greater adiposity of Indian children is of interest in view of the possible effects that foetal programming could have in later life. Follow-up studies of Indian children have suggested that skinfold thickness tracks into early childhood ${ }^{6}$. The adiposity of infants in relation to their body weight, given the 'thin-fat' phenotype and its tracking into later life, is important to characterise when considering initiatives to reduce LBW, since increasing birth weight could be associated with a greater degree of adiposity.

Although there are indications of a relatively greater adiposity in Indian babies ${ }^{4,6}$, it is not known if they truly have a greater total adiposity at birth or whether the adiposity increases disproportionately with increasing birth weight. Given the 'thin-fat' phenotype at birth and the observation that there is a relatively greater accumulation of fat for a given adult body size in Indians ${ }^{7,8}$, it is of interest to ascertain if Indian babies have a similar or steeper gradient of increase in fat with increasing weight. One possibility is to examine and compare relationships between birth weight and arm fat 
area (AFA), as well as the proportion that AFA contributes to mid arm area (arm fat index, $\mathrm{AFI}^{9}$ ). In a recent American study in small-for-gestational age (SGA), appropriate-forgestational age (AGA) and large-for-gestational age (LGA) babies $^{10}$, the calculated AFI increased progressively from 19.2 to 22.2 to $25.3 \%$ across these three categories, respectively. If large Indian babies had a disproportionately greater adiposity, this would have implications for interventions to reduce LBW without considerations of body composition.

While the adiposity of infants is therefore of great interest, their muscle mass may also be important. The total body muscle mass, which has an independent effect on insulin sensitivity and glucose disposal ${ }^{11-14}$, could also determine the risk of developing insulin resistance in adults. Studies on Indian men have indicated that they have a relatively low muscle $\operatorname{mass}^{15-17}$, which is compounded by chronic undernutrition ${ }^{18}$. Arm muscle area (AMA) in 4-year-old children ${ }^{19}$ and adults ${ }^{20}$ is related to birth weight. The AMA at 2-5 months of age of LGA infants has been shown to track into the 4 th year of age more so than AFA in Western infants ${ }^{19}$.

It is necessary to define the pattern of body composition that is prevalent in the Indian population across a range of birth weights. Therefore, we undertook the present study to assess body composition in Indian babies, and further, assessed the relationship of maternal anthropometry with these outcomes.

\section{Subjects and methods}

Subjects were recruited as part of an ongoing prospective study at St. John's Medical College Hospital, Bangalore, India (Muthayya et al., submitted). All pregnant women aged 17-40 years who were below 20 weeks of gestation and registered for antenatal screening at the Department of Obstetrics and Gynecology at St. John's Medical College Hospital from November 2001 to June 2005 were invited to participate in the study. This department usually sees about 2000 deliveries a year, about half of whom are booked within the antenatal care programme. However, many women are booked after the first trimester and some return to their ancestral home for the delivery, and hence could not be approached for recruitment into this study. Women with multiple pregnancies, those with a clinical diagnosis of chronic illness such as diabetes mellitus, hypertension, heart disease and thyroid disease, those who tested positive for hepatitis B (HbSAg), HIV or syphilis (VDRL) infections or who anticipated moving out of the city before delivery were excluded. Of 785 women who consented to be part of the study, 712 women (73 women were excluded) were recruited into the study; 103 were lost to follow-up and 113 delivered in a facility outside St. John's Medical College Hospital. A total of 496 women delivered at St. John's Medical College Hospital; 46 of them were foetal losses and the remaining 450 cases were live births. Anthropometric measurements were obtained for 429 live-born babies. Neonates of mothers who had gestational diabetes mellitus were excluded from the analysis ( $n=21,5 \%$ ), leaving 408 cases whose data have been used in this analysis. The Institutional Ethical Review Board at St. John's Medical College Hospital approved all study procedures, and written informed consent was obtained from each study subject at enrolment.

At the baseline visit, trained research assistants interviewed the study subjects to obtain information on age, education, occupation and obstetric history. Gestational age (in weeks) was calculated from the reported first day of the last menstrual period (LMP). Subsequent ultrasonographic measurements were performed within 2 weeks of the initial visit to confirm gestational age calculated by LMP. A digital balance (Soehnle, Germany) was used to record the weights of all mothers to the nearest $100 \mathrm{~g}$. Measurements of height were made using a stadiometer to the nearest $1 \mathrm{~cm}$. Maternal body mass index (BMI) was calculated from weight and height at baseline $\left(\mathrm{kg} \mathrm{m}^{-2}\right.$ ). Mid upper-arm circumference (MUAC) was measured to the nearest $0.1 \mathrm{~cm}$ using a plastic measuring tape and skinfold thicknesses (biceps, triceps and subscapular) were measured with Holtain callipers (Crymych, UK) for the assessment of body composition using prediction equations ${ }^{21}$.

At birth, infants were weighed to the nearest $10 \mathrm{~g}$ on a standard beam scale balance. They were assigned to SGA, AGA and LGA groups using criteria of the World Health Organization (WHO) ${ }^{9}$. SGA was defined as below the 10th percentile of birth-weight-for-gestational-age, AGA from the 10th to the 89th percentile, and LGA at or above the 90th percentile. However, since we wanted to compare data in the present study with data from a recent American study ${ }^{10}$ which had used birth weight percentiles from an American dataset $^{22}$ to classify the babies, we made an additional classification of the babies in the present study using weight percentiles from Brenner et $a l^{22}$. Based on these cut-offs, 146 or 96 infants were SGA $(<10$ th percentile), while 260 or 306 were AGA (10th to 89th percentile), and two or six were LGA ( $\geq 90$ th percentile) according to the $\mathrm{WHO}^{9}$ or American ${ }^{22}$ birth weight percentiles, respectively. Measurements of length of the infants were made in the supine position using a measuring board anthropometer to the nearest $0.1 \mathrm{~cm}$. MUAC was measured to the nearest $0.1 \mathrm{~cm}$ using a plastic measuring tape and skinfold thicknesses (biceps, triceps and subscapular) were measured with Holtain callipers applied for $5 \mathrm{~s}$ at each measurement, for the assessment of a surrogate of neonatal body fat using the sum of the three skinfold thicknesses. All anthropometric measurements were obtained within the first 48 hours of birth by two trained research assistants throughout the study.

Arm muscle-bone area (AMA) of the neonate was calculated with measures of MUAC and triceps skinfold 
thickness using the formula: AMA $\left(\mathrm{cm}^{2}\right)=($ MUAC $-\pi \times$ triceps $)^{2} / 4 \pi$. A measure of the muscularity of the neonate corrected for size was obtained by calculating the percentage arm muscle area or arm muscle index (AMI) of the neonate using the formula: AMI = [AMA $\left./(\operatorname{MUAC} / 2 \pi)^{2}\right] \times 100$. This measure, which is the ratio of AMA to the cross-sectional area of the arm at the point of measurement of MUAC (MAA), is analogous but reciprocal to the $\mathrm{AFI}^{9}$, which is the ratio of the upper arm fat area (AFA) and the MAA. In absolute terms, the calculated AFA and AMA could represent overestimates of the true AFA and AMA measured by ultrasonography; however, the calculated values correlate well with measured values ${ }^{23}$, and it was our intention to use these as ranking rather than absolute variables.

\section{Statistical analysis}

All analyses were done with the SPSS program (version 13.0; SPSS Inc., Chicago, IL, USA). The analysis focused on the assessment of body composition of the babies, as well as maternal determinants of this body composition. Results are presented as median (interquartile range), as several of the variables exhibited a small but significant deviation from normality. Correlations between birth weight and single skinfold thickness or the sum of skinfold thicknesses and AMA of the neonate were assessed using Pearson's correlation coefficient. Measured and computed anthropometric variables of SGA babies were compared with those of AGA and LGA babies by both one-way analysis of variance (ANOVA) and the Kruskal-Wallis test. Logistic regression models with and without adjustment were used to assess the relationship of maternal anthropometric variables to neonatal body composition. Two-sided $P$-values $<0.05$ were considered statistically significant.

\section{Results}

The mean \pm standard deviation (SD) age of the study participants $(n=408)$ was $24.2 \pm 3.9$ years (range $17-40$ years) and their demographic characteristics are provided in Table 1 . The mean \pm SD birth weight of all newborns was $2.80 \pm 0.44 \mathrm{~kg}$, with a mean gestational age at birth of 38.6 weeks. The anthropometric characteristics of all neonates are also shown in Table 1 . Birth weight was significantly related to each measured skinfold thickness of the babies and the relationships with triceps and subscapular skinfold thickness had very similar slopes, while the slope was slightly lower for biceps skinfold thickness (Fig. 1). Significant relationships were also obtained for the sum of all three skinfold thicknesses as well as for AMA with birth weight, with correlation coefficients of 0.70 for both relationships, $P<0.000$ (Fig. 2), although the slope of the sum of skinfold thicknesses-birth weight relationship was steeper. AMI ranged from 60 to $80 \%$ of the total arm cross-sectional area
Table 1 Maternal characteristics of pregnant women at baseline and infant anthropometry $(n=429)$

\begin{tabular}{|c|c|}
\hline Parameter & $\begin{array}{l}\text { All births } \\
(n=408)\end{array}$ \\
\hline \multicolumn{2}{|l|}{ Maternal characteristics } \\
\hline Age (years)* ${ }^{\star}$ & $24.0(21.0-27.0)$ \\
\hline Time pregnant (weeks by LMP)* & $13.0(10.3-14.3)$ \\
\hline \multicolumn{2}{|l|}{ Parity† } \\
\hline 0 & $238(58.3)$ \\
\hline $1-2$ & $159(39.0)$ \\
\hline$\geq 3$ & $11(2.7)$ \\
\hline \multicolumn{2}{|l|}{ Educational levelt } \\
\hline Up to high school & $257(63.0)$ \\
\hline High school diploma & 77 (17.9) \\
\hline University degree \& above & $88(19.1)$ \\
\hline \multicolumn{2}{|l|}{ Employment status $†$} \\
\hline Employed outside the home & $115(28.2)$ \\
\hline Housewife & $293(71.8)$ \\
\hline \multicolumn{2}{|l|}{ Maternal anthropometry* } \\
\hline Body weight $(\mathrm{kg})$ & $51.2(46.2-57.5)$ \\
\hline Height $(\mathrm{m})$ & $1.55(1.52-1.60)$ \\
\hline BMI $\left(\mathrm{kg} \mathrm{m}^{-2}\right)$ & $21.5(19.2-24.2)$ \\
\hline $\operatorname{MUAC}(\mathrm{cm})(n=401)$ & $24.0(22.0-26.3)$ \\
\hline$\%$ Body fat $(n=404)$ & $28.9(25.1-33.1)$ \\
\hline Fat mass $(\mathrm{kg})(n=404)$ & $14.7(11.3-18.5)$ \\
\hline \multicolumn{2}{|l|}{ Neonatal anthropometry* } \\
\hline Body weight $(\mathrm{kg})$ & $2.81(2.51-3.10)$ \\
\hline Body length $(\mathrm{cm})(n=408)$ & $49.7(48.0-51.2)$ \\
\hline MUAC $(\mathrm{cm})$ & $9.6(9.0-10.2)$ \\
\hline $\mathrm{BSF}(\mathrm{mm})$ & $3.0(2.6-3.4)$ \\
\hline TSF $(\mathrm{mm})$ & $3.8(3.2-4.4)$ \\
\hline SSF (mm) & $3.6(3.0-4.2)$ \\
\hline AMA $\left(\mathrm{cm}^{2}\right)$ & $5.64(4.98-6.26)$ \\
\hline $\operatorname{AFA}\left(\mathrm{cm}^{2}\right)$ & $1.69(1.43-2.05)$ \\
\hline AMI (\%) & $76.7(74.1-78.9)$ \\
\hline AFI (\%) & $23.3(21.0-25.8)$ \\
\hline
\end{tabular}

LMP - last menstrual period; BMI - body mass index; MUAC - mid upper-arm circumference; BSF - biceps skinfold thickness; TSF - triceps skinfold thickness; SSF - subscapular skinfold thickness; AMA - arm muscle area; AFA - arm fat area; AMI - arm muscle index; AFI - arm fat index.

Note: $n=408$ for all variables unless specified otherwise.

${ }^{*}$ Median (interquartile range).

$\dagger n(\%)$.

(MAA) and had an inverse relationship with birth weight $(r=-0.43, P<0.000)$, suggesting an increase in appendicular fat relative to muscle in heavier infants in this group (Fig. 3). The slope of the relationship suggested that the AMI would reduce by about 3.5\% for every $1000 \mathrm{~g}$ increase in birth weight.

In order to facilitate comparisons of skinfold thickness in the present data with earlier reports from India (Pune ${ }^{5}$ and Mysore $^{6}$ ) and the UK (reported in reference 5), we calculated the mean subscapular and triceps skinfold thickness in babies with birth weight ranging from 2800 to $3300 \mathrm{~g}$, who had a mean gestational age of 39 weeks. The mean birth weight was $3040 \mathrm{~g}$, which was similar to the weight of babies in the previous Indian and UK reports 5,6 (Table 2); interestingly, the mean skinfold thickness was closer to the UK data than the Indian data ${ }^{5,6}$. Conversely, calculating skinfold thickness in all babies in the present study at a gestational age of 40 weeks, based on the regression equations in Fig. 1, also yielded values that 

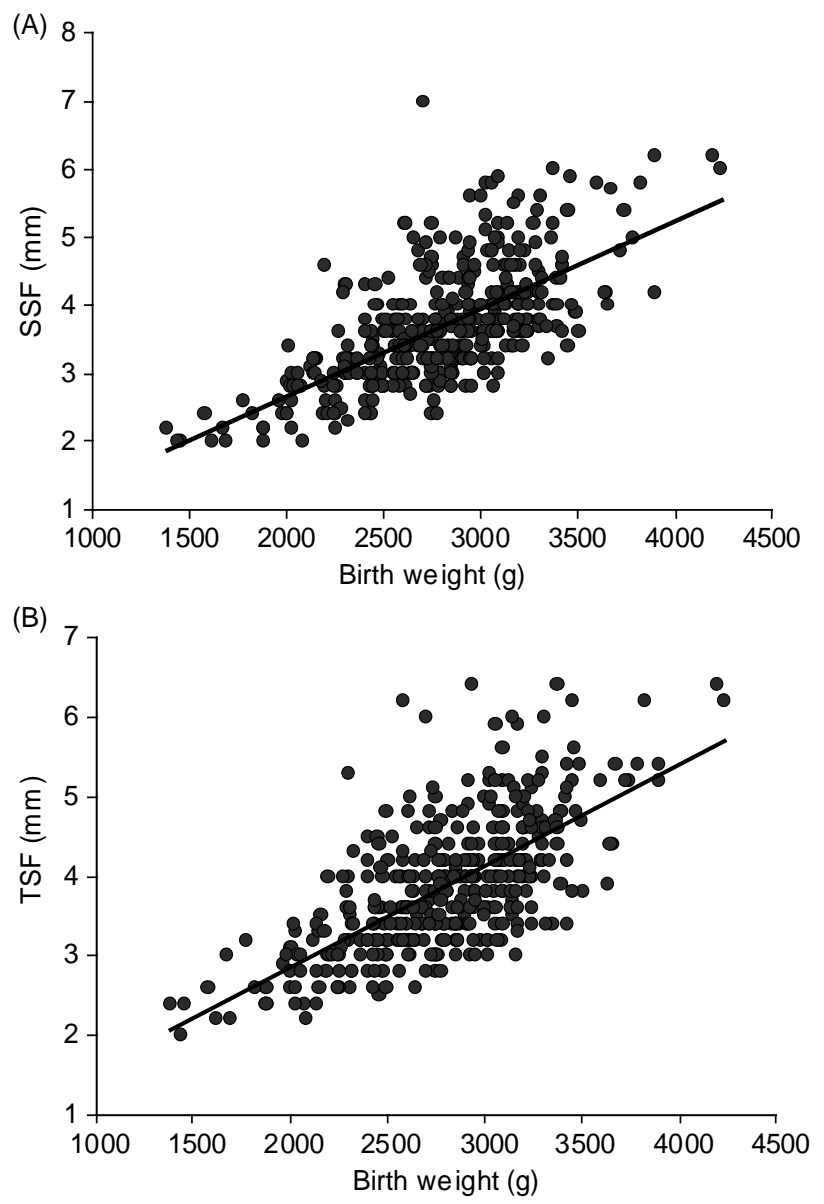

Fig. 1 (A) Scatter plot of subscapular skinfold thickness (SSF) against birth weight. Equation: SSF $(\mathrm{mm})=0.0013 \times$ birth weight $(\mathrm{g})+0.0959, r^{2}=0.4$. Equation including gestational age and gender: SSF $(\mathrm{mm})=0.0013 \times$ birth weight $(\mathrm{g})-0.0214 \times$ gestational age (weeks) $+0.2545 \times$ gender $+0.3831, r^{2}=0.5$.

(B) Scatter plot of triceps skinfold thickness (TSF) against birth weight. Equation: $\operatorname{TSF}(\mathrm{mm})=0.0013 \times$ birth weight $(\mathrm{g})+0.3329$, $r^{2}=0.5$. Equation including gestational age and gender: TSF $(\mathrm{mm})=0.0013 \times$ birth weight $(\mathrm{g})-0.096 \times$ gestational age (weeks) $+0.1966 \times$ gender $+0.3196, r^{2}=0.5$

were similar to the Southampton data ( 4.2 and $4.0 \mathrm{~mm}$ for triceps and subscapular skinfold thickness, respectively).

Group-wise analysis of SGA, AGA and LGA babies based on the birth weight percentiles using both WHO and American standards showed significant differences between groups for all variables. The SGA babies had lower MUAC, sum of skinfold thicknesses and AMA, but had a higher AMI and a lower AFI. Differences between the groups were assessed by both one-way ANOVA and the Kruskal-Wallis test, and were significant for all variables (Table 3). However, in Table 2, mean $\pm \mathrm{SD}$ values have been reported to facilitate comparisons between the present data and the Western values from the literature ${ }^{10}$. The mean and median values in the present study were similar, since there was only a small deviation from normality in the distribution of all anthropometric variables. Median (interquartile range) birth weight and subscapular skinfold thickness were 2.46

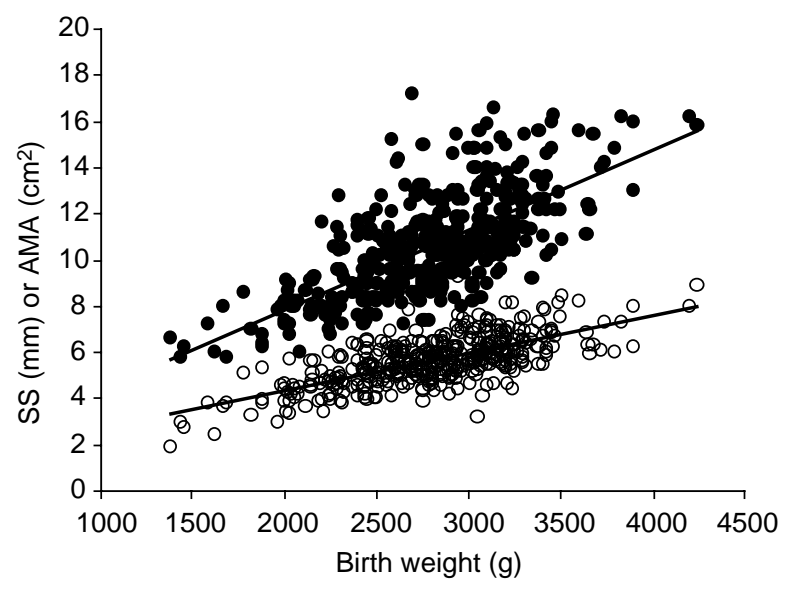

Fig. 2 Scatter plot of the sum of three skinfold thicknesses (biceps, triceps and subscapular) (SS) and arm muscle area (AMA) against birth weight. Equation for SS: SS $(\mathrm{mm})=0.0034 \times$ birth weight $(\mathrm{g})+0.9818, r^{2}=0.5$. Equation including gestational age and gender: SS $(\mathrm{mm})=0.0035 \times$ birth weight $(\mathrm{g})-0.0186 \times$ gestational age (weeks) $+0.5067 \times$ gender $+0.7382, r^{2}=0.5$. Equation for AMA: AMA $\left(\mathrm{cm}^{2}\right)=0.0016 \times$ birth weight (g) $+1.0672, r^{2}=0.5$. Equation including gestational age and gender: AMA $\left(\mathrm{cm}^{2}\right)=0.0017 \times$ birth weight $(\mathrm{g})-0.0089 \times$ gestational age (weeks) $+0.1848 \times$ gender $+1.0511, r^{2}=0.5$

(2.25-2.66) $\mathrm{kg}$ and $3.16(2.80-3.80) \mathrm{mm}$ respectively for SGA babies, $3.03(2.81-3.20) \mathrm{kg}$ and $3.8(3.4-4.4) \mathrm{mm}$ for AGA babies, and 4.20 (4.20-4.24) $\mathrm{kg}$ and 6.1 (6.0-6.2) $\mathrm{mm}$ for LGA babies. All of the measured anthropometric variables were higher in the Indian AGA and SGA groups because the mean weight in these groups was also higher (Table 2). This was because there were fewer children with very low birth weight in the Indian group, and a large group of babies born between 37 and 42 weeks who were either SGA or AGA. There were very few LGA babies in the Indian group $(n=6)$ with a mean birth weight lower than

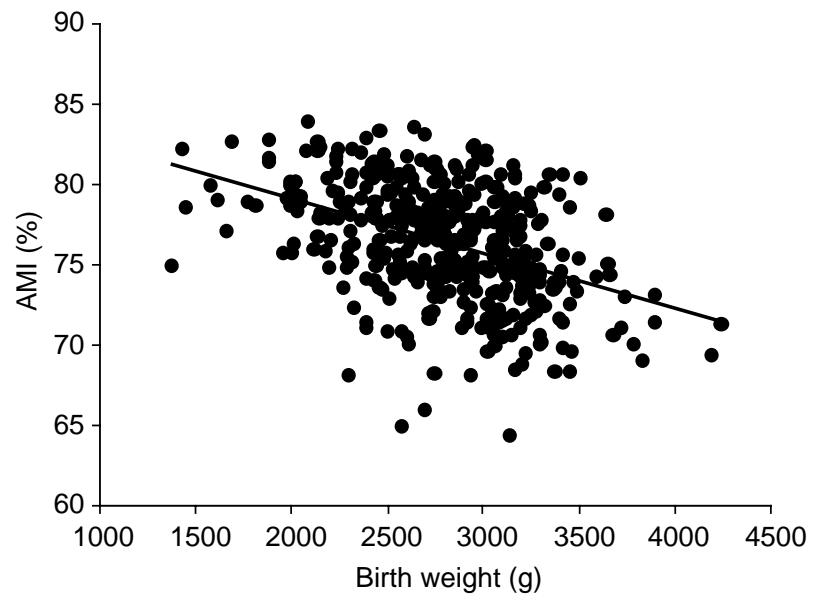

Fig. 3 Scatter plot of arm muscle index (AMI; arm muscle area $\times 100 /$ mid upper-arm cross-sectional area) against birth weight. Equation for AMI: AMI $(\%)=-0.0034 \times$ birth weight (g) $+86.015, r^{2}=0.2$. Equation including gestational age and gender: AMI $(\%)=-0.0036 \times$ birth weight $(\mathrm{g})+0.0239 \times$ gestational age (weeks) $-0.7089 \times$ gender $+88.89, r^{2}=0.2$ 
Table 2 Comparison of mean birth weight and skinfold thicknesses of babies born in the birth weight range $2800-3300 \mathrm{~g}$ in Bangalore (present study), Mysore ${ }^{6}$, Pune $^{5}$ and Southampton ${ }^{5}$

\begin{tabular}{|c|c|c|c|c|}
\hline & Bangalore & Mysore & Pune & Southampton \\
\hline Number & 179 & 589 & 162 & 114 \\
\hline Gestational age (days) & 273 & 273 & 279 & 278 \\
\hline Birth weight $(\mathrm{g})$ & 3040 & $2950^{\star}$ & 3008 & 3066 \\
\hline TSF $(\mathrm{mm})$ & 4.1 & $4.2^{*}$ & $4.6^{*}$ & - \\
\hline $\mathrm{SSF}(\mathrm{mm})$ & 4.0 & $4.4^{*}$ & $4.6^{*}$ & $4.1^{*}$ \\
\hline
\end{tabular}

TSF - triceps skinfold thickness; SSF - subscapular skinfold thickness. *Median.

American babies $(n=16)$. Interestingly, the values of triceps and subscapular skinfold thickness were similar in both LGA groups despite a larger mean birth weight in the American group, leading to a relative difference in AFI in these gestational groups. These data are plotted in Fig. 4 and it is evident that the slope of the AFI-birth weight relationship across different gestational groups was higher in the Indian babies ( 4.5 vs. $2.3 \%$ per $\mathrm{kg}$ birth weight in Indian and American babies, respectively). The difference in the slope appeared to be due to a relatively larger increase in arm fat area (numerator) in relation to the arm area (denominator) in the LGA group of Indian babies.

In addition, the associations of maternal anthropometric variables measured at early pregnancy to the weight, length, body fat and muscle compartments of the neonate were studied using logistic regression analysis. Birth weight was significantly associated with most maternal anthropometric measures. Birth weights were not different between male and female babies. Length at birth was related to most maternal anthropometric parameters. However, after adjustment for maternal weight at baseline, baby weight and gender, only maternal height remained significantly associated with length at birth (Table 4); gender was also adjusted for because there was a significant difference in length between male and female babies. We also assessed the associations between babies' body composition at birth and maternal anthropometry. Although babies' AMA showed several significant bivariate associations with all maternal anthropometric parameters, no significant associations were found on multivariate analysis after adjusting for maternal weight and birth weight. Similarly, the sum of skinfold thicknesses at birth was associated by bivariate analysis with most maternal anthropometric characteristics except height. On multivariate analysis, after adjustment for maternal weight and birth weight, fat-free mass was found to have a significant associative trend although the individual odds ratios of the lowest and second tertiles were not significant compared with the third (reference) tertile (odds ratio and 95\% confidence interval: 0.38 and $0.13-1.11$ for first tertile, 1.10 and $0.52-2.36$ for second tertile; $P<0.02$ ).

\section{Discussion}

The short-term adverse outcomes associated with LBW are of great concern, and studies on the association of LBW with adverse long-term outcomes such as the risk of diabetes and cardiovascular disease in adulthood ${ }^{24,25}$ add to this concern. Studies have shown that Indian babies have a lower birth weight than their Western counterparts and that the body fat is relatively preserved in these babies, leading to their description as 'thin-fat'. The implicit association that can be derived is that of increased body fat at birth, tracking into adulthood depending on environmental constraints. Increasing birth weight in such babies might also imply that the accumulation of fat is disproportionately more as birth weight increases. This is not unlikely, as adult Indian populations have been shown

Table 3 Weight and anthropometric characteristics of SGA, AGA and LGA babies in the present study $(n=408)$ and comparison with American babies ${ }^{10}$

\begin{tabular}{|c|c|c|c|c|c|c|}
\hline & Weight (kg) & MUAC (cm) & AMA $\left(\mathrm{cm}^{2}\right)$ & AFA $\left(\mathrm{cm}^{2}\right)$ & TSF (mm) & $\mathrm{SSF}(\mathrm{mm})$ \\
\hline \multicolumn{7}{|c|}{ Indian babies } \\
\hline \multicolumn{7}{|c|}{ Using WHO centiles ${ }^{9}$} \\
\hline SGA $(n=146)$ & $2.43 \pm 0.31$ & $9.00 \pm 0.85$ & $5.03 \pm 0.90$ & $1.46 \pm 0.37$ & $3.43 \pm 0.69$ & $3.26 \pm 0.73$ \\
\hline AGA $(n=260)$ & $3.00 \pm 0.35$ & $9.90 \pm 0.83$ & $5.94 \pm 0.97$ & $1.91 \pm 0.46$ & $4.10 \pm 0.78$ & $3.93 \pm 0.82$ \\
\hline LGA $(n=2)$ & $4.22 \pm 0.03$ & $12.25 \pm 0.35$ & $8.41 \pm 0.65$ & $3.54 \pm 0.04$ & $6.30 \pm 0.14$ & $6.10 \pm 0.69$ \\
\hline \multicolumn{7}{|c|}{ Using American centiles ${ }^{22}$} \\
\hline SGA $(n=96)$ & $2.32 \pm 0.31$ & $8.80 \pm 0.90$ & $4.90 \pm 0.95$ & $1.37 \pm 0.37$ & $3.30 \pm 0.69$ & $3.10 \pm 0.71$ \\
\hline AGA $(n=306)$ & $2.93 \pm 0.34$ & $9.80 \pm 0.80$ & $5.90 \pm 0.94$ & $1.85 \pm 0.44$ & $4.02 \pm 0.75$ & $3.90 \pm 0.79$ \\
\hline $\mathrm{LGA}(n=6)$ & $3.96 \pm 0.22$ & $11.50 \pm 0.79$ & $7.43 \pm 1.03$ & $3.07 \pm 0.45$ & $5.80 \pm 0.52$ & $5.70 \pm 0.75$ \\
\hline \multirow{2}{*}{\multicolumn{7}{|c|}{$\begin{array}{l}\text { American babies } \\
\text { Using American centiles }{ }^{22}\end{array}$}} \\
\hline & & & & & & \\
\hline SGA $(n=74)$ & $1.94 \pm 0.45$ & $8.10 \pm 1.10$ & $4.20 \pm 1.10$ & $1.05^{\star}$ & $2.90 \pm 0.50$ & $2.70 \pm 0.60$ \\
\hline AGA $(n=30)$ & $2.41 \pm 0.65$ & $8.90 \pm 1.20$ & $5.00 \pm 1.30$ & $1.45^{\star}$ & $3.60 \pm 0.90$ & $3.40 \pm 0.80$ \\
\hline LGA $(n=16)$ & $4.34 \pm 0.35$ & $12.40 \pm 0.90$ & $9.00 \pm 1.30$ & $3.15^{\star}$ & $5.80 \pm 1.60$ & $5.90 \pm 1.70$ \\
\hline
\end{tabular}

SGA - small-for-gestational-age; AGA - adequate-for-gestational-age; LGA - large-for-gestational-age; MUAC - mid upper-arm circumference; AMA arm muscle area; AFA - arm fat area; TSF - triceps skinfold thickness; SSF - subscapular skinfold thickness; WHO - World Health Organization.

Values are expressed as mean \pm standard deviation; median values (which were very similar to the mean values) not reported for Indian data to facilitate comparisons. All comparisons between birth weight groups were significantly different $(P<0.001)$ by one-way analysis of variance and the Kruskal-Wallis test in the present study.

${ }^{*}$ Calculated from data on SGA, AGA and LGA babies in reference 10. 
Body composition of south Indian neonates

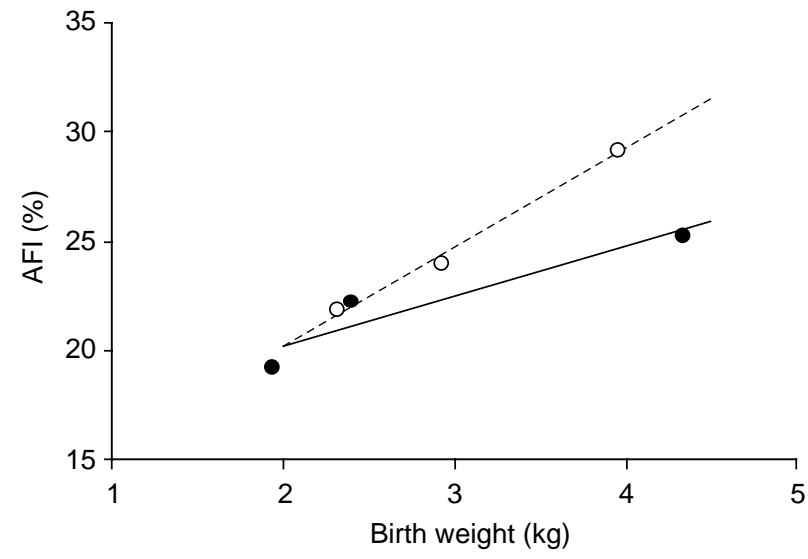

Fig. 4 Comparison of mean arm fat index (AFI; arm fat area $\times 100 /$ mid upper-arm cross-sectional area) in small-forgestational-age, adequate-for-gestational-age and large-for-gestational-age babies in the present study $(\bigcirc)$ compared with values calculated from reported mean mid upper-arm circumference and triceps skinfold thickness in an American study (Koo et al. $\left.{ }^{10}, \bullet\right)$. Mean values used to facilitate comparisons. Dashed line (equation: $\mathrm{AFI}=0.0045 \times$ birth weight $(\mathrm{kg})+0.5465)$ represents the fitted line to these data for the present study, and the solid line (equation: $\mathrm{AFI}=0.0023 \times$ birth weight $(\mathrm{kg})+0.4564)$ represents the fitted line for the American dataset. The slopes of the two regression lines for the American and Indian babies were not significantly different

to have a higher percentage body fat for a given BMI than Western populations ${ }^{8,26}$, and it is worth assessing if a similar steeper slope in the adiposity-birth weight relationship is present in Indian babies. This is possible if one considers the use of surrogates of adiposity such as the relationship between measured skinfold thicknesses or AFI and body weight.
The relationship between skinfold thicknesses and birth weight allowed for comparisons of the present study with earlier studies in the UK, in Southampton, and in India, in Pune and Mysore ${ }^{5,6}$. Using the equation derived in the present study between subscapular skinfold thickness and birth weight in the whole group, we could predict the mean subscapular or triceps skinfold thickness for the reported mean birth weight in those studies. In the UK study, the predicted and measured mean subscapular skinfold thicknesses were identical. In contrast, for the birth weights reported in Pune ${ }^{5}$ and Mysore $^{6}$, we found that the measured subscapular and triceps skinfold thicknesses were about $0.4-0.5 \mathrm{~mm}$ higher than the predicted value. These observations suggest that this index of adiposity in the present data was more similar to the UK data than the Indian data. The reason for this discrepancy is not clear; it is unlikely to be methodological as all sites reported good measurement practices and all excluded mothers with gestational diabetes mellitus. The same findings were present when comparisons of skinfold thickness between the datasets was performed with birth weights in the present study constrained to similar ranges as reported earlier ${ }^{5}$. It is also pertinent to note in these comparisons that: (1) in the Mysore $^{6}$ data, the birth measurements were adjusted to 40 weeks by linear regression (details were not provided); (2) the Pune ${ }^{5}$ and $\mathrm{UK}^{5}$ data were apparently not adjusted for gestational age (the proportion of SGA and LGA could widely differ in this birth weight range); and (3) the difference in the skinfold value between all these reports is about $10-15 \%$, which might simply be accounted for by measurement error (inter- and intra-measurer errors can approach 1 to $1.5 \mathrm{~mm}$

Table 4 OR $(95 \% \mathrm{Cl})$ for weight at birth and length at birth in relation to maternal anthropometry at baseline $(n=408)$

\begin{tabular}{|c|c|c|c|c|c|c|}
\hline \multirow[b]{3}{*}{ Variable } & \multicolumn{2}{|c|}{ Maternal anthropometry } & \multicolumn{2}{|c|}{ Weight at birth } & \multicolumn{2}{|c|}{ Length at birth } \\
\hline & \multirow[b]{2}{*}{ Tertile } & \multirow[b]{2}{*}{ Median (IQR) } & \multicolumn{2}{|c|}{ OR $(95 \% \mathrm{Cl})$} & \multicolumn{2}{|c|}{ OR $(95 \% \mathrm{Cl})$} \\
\hline & & & Univariate & Multivariate & Univariate & Multivariate \\
\hline \multirow[t]{3}{*}{ Maternal weight $(\mathrm{kg})$} & 1 & $44.2(41.5-46.2)$ & $2.29(1.38-3.79)$ & & $2.57(1.52-4.33)$ & \\
\hline & 2 & $51.2(49.6-53.2)$ & $0.86(0.50-1.47)$ & & $1.46(0.85-2.50)$ & \\
\hline & 3 & $61.6(57.4-67.0)$ & 1.00 & & 1.00 & \\
\hline$P$-value & & & $<0.001$ & & $<0.001$ & \\
\hline \multirow[t]{3}{*}{ Maternal height (m) } & 1 & $1.49(1.47-1.52)$ & $1.29(0.77-2.15)$ & $1.07(0.63-1.83)$ & $2.68(1.53-4.7)$ & $2.73(1.41-5.28)$ \\
\hline & 2 & $1.55(1.55-1.57)$ & $1.02(0.59-1.76)$ & $0.92(0.52-1.60)$ & $2.07(1.15-3.74)$ & $2.57(1.28-5.17)$ \\
\hline & 3 & $1.60(1.60-1.63)$ & 1.00 & 1.00 & 1.00 & 1.00 \\
\hline$P$-value & & & 0.336 & 0.82 & 0.001 & 0.008 \\
\hline \multirow[t]{3}{*}{$\operatorname{MUAC}(\mathrm{cm})$} & 1 & $21.2(20.2-22.0)$ & $2.26(1.34-3.82)$ & $1.39(0.66-2.95)$ & $2.18(1.28-3.71)$ & $1.02(0.43-2.45)$ \\
\hline & 2 & $24.0(23.2-25.0)$ & $1.85(1.08-3.17)$ & $1.45(0.79-2.66)$ & $1.98(1.15-3.42)$ & $1.38(0.69-2.76)$ \\
\hline & 3 & $27.2(26.3-29.1)$ & 1.00 & 1.00 & 1.00 & 1.0 \\
\hline$P$-value & & & 0.002 & 0.49 & 0.01 & 0.52 \\
\hline \multirow[t]{3}{*}{ Fat mass (kg) } & 1 & $10.4(8.98-11.3)$ & $1.98(1.17-3.34)$ & $0.95(0.39-2.29)$ & $2.18(1.28-3.7)$ & $1.03(0.35-2.94)$ \\
\hline & 2 & $14.7(13.5-15.8)$ & $1.74(1.03-2.95)$ & $1.17(0.61-2.26)$ & $1.88(1.1-3.21)$ & $1.34(0.63-2.86)$ \\
\hline & 3 & $20.9(18.5-23.8)$ & 1.00 & 1.00 & 1.00 & 1.00 \\
\hline$P$-value & & & 0.01 & 0.69 & 0.01 & 0.58 \\
\hline \multirow[t]{3}{*}{ FFM (kg) } & 1 & 32.9 (31.1-33.9) & $2.90(1.72-4.91)$ & $2.86(1.20-6.78)$ & $3.32(1.93-5.71)$ & $2.16(0.78-5.95)$ \\
\hline & 2 & $36.6(35.7-37.5)$ & $1.45(0.84-2.49)$ & $1.44(0.75-2.77)$ & $1.97(1.13-3.43)$ & $1.80(0.84-3.87)$ \\
\hline & 3 & $41.3(39.8-44.2)$ & 1.00 & 1.00 & 1.00 & 1.00 \\
\hline$P$-value & & & $<0.001$ & 0.04 & $<0.001$ & 0.27 \\
\hline
\end{tabular}

$\mathrm{OR}$ - odds ratio; $\mathrm{Cl}$ - confidence interval; IQR - interquartile range; MUAC - mid upper-arm circumference; FFM - fat-free mass. 
in adults ${ }^{27}$ and could be greater in the more hydrated tissue of infants).

The comparison of measured anthropometry and derived indices such as the AFI with American babies ${ }^{10}$ also suggested that the Indian babies in the present study were similar to Western babies. In the SGA and AGA groups, the mean skinfold thickness values were different but proportionate to the mean birth weights, which were higher in the Indian babies. This might be due to the proportion of babies who were born at less than 37 weeks; in the American data, this proportion was 50, 60 and 0\% respectively in SGA, AGA and LGA groups, while in the Indian babies it was 8, 12 and 0\% respectively. This makes comparisons between datasets difficult; however, the anthropometric pattern changed in the LGA babies. Even though the mean birth weight of the American babies was higher in the American LGA group, the mean size of the triceps and subscapular skinfold thickness was similar in both groups. Therefore, AFI was higher in the Indian babies, resulting in an apparently steeper slope of the relationship between AFI and birth weight across the different gestational groups in the Indian babies (Fig. 4), although there is some uncertainty about this owing to the low number of babies in the LGA group. This also suggests that the 'thin-fat' paradigm may not apply to the SGA and AGA babies in this group, although the indication (because of the relatively small numbers) is that it may apply to LGA babies. AFI is analogous to percentage body fat and, in studies where both parameters were measured $^{10}$, a comparison of the relationship of AFI or percentage body fat with mean birth weight across gestational groups showed that both increase significantly. Neonatal body composition could track into childhood and adulthood. The triceps skinfold thickness has been shown to be preserved at 6 years in an Indian cohort ${ }^{6}$, and from a metabolic viewpoint, measures of insulin resistance were greatest in 8-year-old children who were born small but retained or increased their adiposity at 8 years ${ }^{28}$.

Since there are well-defined genetic and environmental parental parameters such as parental size, maternal food intake, physical activity and circulating concentrations of nutrients and metabolites ${ }^{29-31}$ that are related to birth weight outcomes, it is of interest to assess what maternal anthropometric parameters are related specifically to body composition outcomes in the baby. Length at birth was significantly associated with maternal height after adjusting for maternal weight, birth weight and gender. Indices of lean mass in the mother were similarly predictive of baby length. Indices of muscularity or fatness in the baby, although univariately associated with several maternal anthropometric measures, were not significantly associated with any maternal anthropometric variable, except for an association between maternal fat-free mass and sum of skinfold thicknesses at birth after adjusting for birth weight and maternal weight. Particularly for this variable, it would appear that mothers in the lowest tertile of fat-free mass would have a low chance of delivering an adipose baby.

In conclusion, the prevention of SGA is a matter of importance and priority in reducing immediate adverse outcomes after birth. However, this should be addressed appropriately, particularly if there is a fat preserving compulsion $^{30}$, since it is possible that a larger baby with greater fat mass may not represent the most optimal longterm outcome.

\section{Acknowledgements}

We greatly appreciate the assistance of Nancy Nanditha, V Manjula, MN Selvi and V Mercy in the collection and entry of data. We thank the women and their infants who participated in this study and the doctors, nurses and laboratory technicians who made this study possible.

S.M. was involved in study design and implementation, data analysis and writing of the manuscript. P.D. was involved in study design, implementation and data entry. T.T. was involved in data analysis and write-up. M.V. was involved in study design, data analysis and write-up. A.M., R.M., A.T. and S.B. identified study subjects and provided facilities for the collaborative research. A.V.K. was involved in study design, data analysis and writing of the manuscript. The authors have no conflicts of interest.

\section{References}

1 Chhabra P, Sharma AK, Grover VL, Aggarwal OP. Prevalence of low birth weight and its determinants in an urban resettlement area of Delhi. Asia Pacific Journal of Public Health 2004; 16: 95-8.

2 Bang AT, Reddy HM, Bang RA, Deshmukh MD. Why do neonates die in rural Gadchiroli, India? (Part II): estimating population attributable risks and contribution of multiple morbidities for identifying a strategy to prevent deaths. Journal of Perinatology 2005; 25(Suppl. 1): S35-43.

3 Hales CN, Barker DJP, Clark PMS, Cox LJ, Fall C, Osmond C, Winter PD. Fetal and infant growth and impaired glucose tolerance at age 64. British Medical Journal 1991; 303: 1019-22.

4 Yajnik CS, Lubree HG, Rege SS, Naik SS, Deshpande JA, Deshpande SS, et al. Adiposity and hyperinsulinemia in Indians are present at birth. Journal of Clinical Endocrinology and Metabolism 2002; 87: 5575-80.

5 Yajnik CS, Fall CHD, Coyaji KJ, Hirve SS, Rao SS, Barker DJP et al. Neonatal anthropometry: the thin-fat Indian baby. The Pune Maternal Nutrition Study. International Journal of Obesity and Related Metabolic Disorders 2003; 27: 173-80.

6 Krishnaveni GV, Hill JC, Veena SR, Leary SD, Saperia J, Chachyamma KJ, et al. Truncal adiposity is present at birth and in early childhood in south Indian children. Indian Pediatrics 2005; 42: 527-38.

7 Dudeja V, Misra A, Pandey RM, Devina G, Kumar G, Vikram NK. BMI does not accurately predict overweight in Asian Indians in northern India. British Journal of Nutrition 2001; 86: $105-12$.

8 WHO Expert Consultation. Appropriate body mass index for Asian populations and its implication for policy and implementation strategies. Lancet 2004; 363: 157-63.

9 World Health Organization (WHO). Physical Status: The Use and Interpretation of Anthropometry. Report of a WHO 
Expert Committee. WHO Technical Report Series No. 854. Geneva: WHO, 1995.

10 Koo WW, Walters JC, Hockman EM. Body composition in neonates: relationship between measured and derived anthropometry with dual-energy X-ray absorptiometry measurements. Pediatric Research 2004; 56: 694-700.

11 Dela F, Larsen JJ, Mikines KJ, Ploug T, Petersen LN, Galbo H. Insulin stimulated muscle glucose clearance in patients with NIDDM. Effects of one legged physical training. Diabetes 1995; 44: 1010-20

12 Ebeling P, Bourey R, Koranyi L, Tuominen JA, Groop LC, Henriksson $\mathrm{J}$, et al. Mechanism of enhanced insulin sensitivity in athletes. Increased blood flow, muscle glucose transport protein (glut-4) concentrations and glycogen synthase activity. Journal of Clinical Investigation 1993; 92: 1623-31.

13 Houmard JA, Egan PC, Neufer PD, Friedman JE, Wheeler WS, Israel RG, et al. Elevated skeletal muscle glucose transporter levels in exercise-trained middle aged men. American Journal of Physiology 1991; 261: E437-43.

14 Poehlman ET, Dvorak RV, DeNino WF, Brochu M, Ades PA. Effects of resistance training and endurance training on insulin sensitivity in nonobese, young women: a controlled randomized trial. Journal of Clinical Endocrinology and Metabolism 2000; 85: 2463-8.

15 Chowdhury B, Lantz H, Sjostrom L. Computed tomographydetermined body composition in relation to cardiovascular risk factors in Indian and matched Swedish males. Metabolism 1996; 45: 634-44.

16 Lee RC, Wang Z, Heo M, Ross R, Janssen I, Heymsfield SB. Total body skeletal muscle mass: development and cross validation of anthropometric prediction models. American Journal of Clinical Nutrition 2000; 72: 796-803.

17 Song M-Y, Kim J, Horlick M, Wang J, Pierson RN Jr, Moonseong $\mathrm{H}$, et al. Prepubertal Asians have less limb skeletal muscle. Journal of Applied Physiology 2002; 92: 2285-91.

18 Kurpad AV, Regan MM, Raj T, Vasudevan J, Kuriyan R, Gnanou $\mathrm{J}$, et al. Lysine requirement of chronically undernourished adult Indian subjects, measured by the $24 \mathrm{~h}$ indicator amino acid oxidation and balance technique. American Journal of Clinical Nutrition 2003; 77: 101-8.

19 Hediger ML, Overpeck MD, Kuczmarski RJ, McGlynn A, Maurer KR, Davis WW. Muscularity and fatness of infants and young children born small- or large-for-gestational-age. Pediatrics 1998; 102: E60.
20 Phillips DI. Relation of fetal growth to adult muscle mass and glucose tolerance. Diabetic Medicine 1995; 12: 686-90.

21 Durnin JVGA, Womersley J. Estimates of total body fat from skinfold thickness: measurements on 481 men and women aged from 16 to 72 years. British Journal of Nutrition 1974; 32: 77-9.

22 Brenner WE, Edelman DA, Hendricks CH. A standard of fetal growth for the United States of America. American Journal of Obstetrics and Gynecology 1976; 126: 555-64.

23 Pereira-da-Silva L, Gomes JV, Clington A, Videira-Amaral JM, Bustamante SA. Upper arm measurements of healthy neonates comparing ultrasonography and anthropometric methods. Early Human Development 1999; 54: 117-28.

24 Barker DJP. Mothers, Babies, and Health in Later Life, 2nd ed. Edinburgh/New York: Churchill Livingstone, 1998.

25 Mi J, Law C, Zhang K, Osmond C, Stein C, Barker D. Effects of infant birthweight and maternal body mass index in pregnancy on components of the insulin resistance syndrome in China. Annals of Internal Medicine 2000; 132: $253-60$

26 Bhat DS, Yajnik CS, Sayyad MG, Raut KN, Lubree HG, Rege SS, et al. Body fat measurement in Indian men: comparison of three methods based on a two-compartment model. International Journal of Obesity and Related Metabolic Disorders 2005; 29: 842-8.

27 Lohman TG, Roche AF, Martorell R. Anthropometric Standardization Reference Manual. Champaign, IL: Human Kinetics Publishers, 1988.

28 Bavdekar A, Yajnik CS, Fall CHD, Bapat S, Pandit AN, Deshpande V, et al. Insulin resistance syndrome in 8-yearold Indian children: small at birth, big at 8 years, or both? Diabetes 1999; 48: 2422-9.

29 Rao S, Yajnik CS, Kanade A, Fall CH, Margetts BM, Jackson $\mathrm{AA}$, et al. Intake of micronutrient-rich foods in rural Indian mothers is associated with the size of their babies at birth: Pune Maternal Nutrition Study. Journal of Nutrition 2001; 131: $1217-24$.

30 Yajnik CS. Early life origins of insulin resistance and type 2 diabetes in India and other Asian countries. Journal of Nutrition 2004; 134: 205-10.

31 Muthayya S, Kurpad AV, Duggan CP, Bosch RJ, Dwarkanath $\mathrm{P}$, Mhaskar A, et al. Maternal vitamin $\mathrm{B}_{12}$ status is a risk factor for intrauterine growth retardation in south Indians. European Journal of Clinical Nutrition 2006 Jan 11; [Epub ahead of print]. 